\title{
Hegemonía y alternativas en las políticas educativas para la infancia en Colombia: sujetos, discursos y prácticas $(1982-2015)^{1}$
}

\author{
Hegemony and alternatives in education policies for children in Colombia: \\ subjects, discourses and practices (1982 - 2015) \\ Hegemonia e alternativas nas políticas educacionais para a infância na \\ Colômbia: sujeitos, discursos e práticas (1982-2015)
}

Cecilia Rincón Verdugo ${ }^{2}$

Universidad Distrital Francisco José de Caldas(Colombia)

Ana Virginia Triviño R. ${ }^{3}$

Universidad Distrital Francisco José de Caldas (Colombia)

Recepción: 25/04/2017

Evaluación: 17/05/2015

Aceptación: 05/05/2017

Artículo de Reflexión

DOI: https://doi.org/10.19053/01227238.6246

\begin{abstract}
RESUMEN
Desde una historia interpretativa, Educación (115/94) y el Código de indagamos por el significado, el sentido, Infancia (1098 /2006), son discursos que las transformaciones y los alcances de se han ido configurando por las tensiones la política educativa para la infancia. Se entre las propuestas hegemónicas y las develó cómo las reformas educativas construcciones alternativas lideradas por promovidas desde la Constitución diferentes grupos sociales y políticos. Política de 1991, la Ley General de Estas tensiones en clave de tiempo,

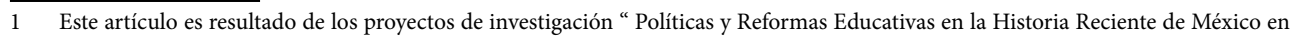
el Contexto Latinoamericano: tensiones, formas de articulación y alternativas pedagógicas en la Línea Reformas Educativas en la Historia Reciente de América Latina: Rasgos, tendencias y experiencias, del grupo APPeAL de México, Argentina y Colombina adscrito a la Facultad de Filosofía de la Universidad Nacional Autónoma de México y el proyecto Hegemonía y alternativas en las políticas educativas para la infancia en Colombia: Sujetos, discursos y prácticas, 1982 - 2015. El proyecto inicia en febrero de 2016 y es financiado por el Centro de Investigaciones y Desarrollo Científico de la Universidad Distrital Francisco José de Caldas.

2 Doctora en Pedagogía, Universidad Nacional Autónoma de México UNAM y Magíoster en Estructuras y Procesos del Aprendizaje. Directora, Psicopedagoga de la Universidad Pedagógica y Tecnológica de Colombia-Tunja. Directora del Grupo de Investigación Infancias reconocido por Colciencias. Coordinadora de la Maestría en Infancia y Cultura. Directora de APPEAL Colombia. Email: rinconceci@yahoo.com

3 Co-investigadora, Magíster en Investigación Social Interdisciplinaria y Licenciada en Ciencias Sociales de la Universidad Distrital Francisco José de Caldas e investigadora del grupo Infancias/ Programa Alternativas Pedagógicas y Prospectiva Educativa en América Latina - APPeAL.
\end{abstract}


muestran que las transformaciones educativas hunden sus raíces en propuestas alternativas que interpelan tanto los planteamientos hegemónicos como la realidad educativa del país. El estudio se inscribe en una visión histórica que recupera diferentes aspectos de la humanidad como la cultura, las significaciones, los sujetos, los saberes, las prácticas y los discursos; elementos que se resignifican y cobran sentido en la medida que pueden ser asumidos como fuente de información. La investigación se desarrolló desde la metodología cualitativa documental que centra la mirada en la producción discursiva de la política educativa, la pedagogía y la educación en unos periodos establecidos. Discursos que se constituyeron en el archivo documental desde los cuales fue posible develar las intenciones, los sentidos y las significaciones de quienes los produjeron, dando cuenta de las transformaciones y contribuciones alcanzadas en materia de la educación para la infancia en este período de tiempo.

Palabras clave: Hegemonía, alternativa, reforma educativa, política, infancia, discursos.

\section{ABSTRACT}

It was studied from theinterpretive history, the meaning; sense; transformations and scope of education policy for children. This paper reveals how the education reforms promoted since the enactment of the Political Constitution of 1991, the General Education Law (115/94) and the Children's Code (1098/2006) constitute discourses shaped by tensions between the hegemonic proposals and alternative constructions led by different social and political groups. These tensions, over time, show that the educational transformations sink their roots in alternative proposals that address both the hegemonic approaches and the educational reality of the country. The study is part of a historical vision that recovers different aspects of humanity such as culture, meanings, subjects, knowledge, practices and discourses; all these, elements that can be resignified and become meaningful to the extent that they can be assumed as a source of information.This research used the qualitative documentary methodology focused on the discursive production of education policy, pedagogy, and education in established periods. These discourses made up the documentary archive where it was possible to unveil the intentions, senses and meanings of those who produced them. Transformations and contributions achieved in the field of children's education, during this period, are explained.

Keywords: Hegemony, alternative, education reform, policy, childhood, discourses.

\section{RESUMO}

A partir de uma história interpretativa, indagamos pelo significado, pelo sentido, pelas transformações e pelos alcances da política educativa para a infância. Foi revelado como as reformas educacionais promovidas a partir da Constituição Política de 1991, a Lei Geral de Educação (115/94) e o Código de Infância (1098/2006) são discursos que se configuraram pelas tensões entre as propostas hegemônicas e as construções alternativas lideradas por 
diferentes grupos sociais e políticos. Estas tensões momentos chave mostram que as transformações educativas fundam suas raízes em propostas alternativas que interpelam tanto as abordagens hegemônicas como a realidade educativa do país. O estudo se insere em uma visão histórica que recupera diferentes aspectos da humanidade como a cultura, as significações, os sujeitos, os saberes, as práticas e os discursos, elementos que ressignificam e cobram sentido na medida em que podem ser assumidos como fonte de informação. A pesquisa se desenvolveu a partir da metodologia qualitativa documental, que centra sua visão na produção discursiva da política educacional, a pedagogia e a educação nos períodos estabelecidos. Discursos que se constituíram no arquivo documental a partir dos quais foi possível revelar as intenções, os sentidos e as significações de quem as produziram, dando conta das transformações e contribuições alcançadas em matéria de educação para a infância neste período de tempo.

Palavras-chave: Revista História da Educação Latino-americana, Hegemonia, alternativa, reforma educativa, política, infância, discursos.

\section{INTRODUCCIÓN}

En la actualidad se observa una preocupación de la sociedad por la infancia, este creciente interés tiene que ver con el reconocimiento a los niños como actores y sujetos de derechos y políticas; esta dinámica ha obligado a la administración pública a asumir como prioridad en sus planes de desarrollo una política educativa para la infancia a fin de disminuir las brechas de desigualdad e inequidad social que existen en nuestro país, acuerdos que exigen brindar una educación inicial que garantice el ingreso temprano al jardín infantil y la escuela, su permanencia y el acceso a las herramientas de la cultura indispensables para superar las inequidades generadas desde los primeros años de vida.

Hoy de cara a las reformas educativas, se constata que la atención y educación de la infancia es una tarea inaplazable y frente al compromiso asumido, se observa que el Ministerio de Educación Nacional después de veinte años de haber sido promulgada la Ley General, aún no ha implementado y garantizado el derecho a la educación consagrado en la Ley 115, Ley General de Educación (1994), en donde se propuso brindar y garantizar tres grados de educación en el nivel inicial y preescolar.

En el diagnóstico realizado por la Misión de Ciencia, Educación y Desarrollo ${ }^{4}$, sobre la educación inicial y preescolar se señala la siguiente problemática: Baja cobertura, distribución inequitativa de la oferta pública existente, desarticulación entre la educación preescolar formal y los diferentes programas de atención a la infancia, prevalencia de la falsa idea de que es fácil educar a los niños pequeños y que por ello cualquiera puede hacerlo sin tomar conciencia de la importancia

4 Misión de Ciencia, Educación y Tecnología, Colombia al Filo de la Oportunidad (Bogotá, COLCIENCIAS, Tercer Mundo Editores, 1996), 139-140 . 
decisiva que tiene la educación temprana en el desarrollo humano, carencia de infraestructura, apoyo tecnológico y material pedagógico adecuado para el fomento de la creatividad, inexistencia de sistemas de detección temprana de talentos y vocaciones especiales y de competencias o deficiencias mentales y sensoriales.

Nos interesa específicamente en este proyecto, analizar los alcances que las reformas y las políticas educativas para la infancia han tenido en la historia reciente de Colombia e interpretar las respuestas que diferentes sectores han dado a esta problemática, por tanto el objeto del presente trabajo se orienta a develar los significados, los sentidos, las transformaciones y los alcances de esta política; entendida como una reforma promovida desde la Constitución Política de 1991 y la Ley General de Educación (115/94) las cuales se han configurado en las tensiones entre las propuestas hegemónicas y las construcciones alternativas lideradas por diferentes grupos sociales, académicos y políticos del país.

Desde esta perspectiva, este estudio de carácter histórico interpretativo plantea como problema de investigación ¿Cuál ha sido el significado, el sentido, las transformaciones y los alcances de la política educativa para la infancia, en el período comprendido entre 1982 a 2015 en Colombia? En este sentido esta investigación reflexionó sobre ¿Quiénes son los sujetos que han promovido y participado en estas reformas educativas? ¿Qué efectos han producido sobre el conjunto de la educación inicial y preescolar? ¿Qué transformaciones en los sujetos, los discursos y las prácticas pedagógicas se despliegan desde las políticas educativas y los programas de gobierno en el marco de esta reforma? ¿Cuáles son y qué dicen los lineamientos, currículos y estándares que se han producido para la educación inicial y preescolar en el país?

El enfoque teórico de este estudio, lo sustentamos en la Nueva Historia que propone comprender y explicar el pasado, los procesos de conformación social, teniendo en cuenta que quien construye ese pasado son seres humanos, sujetos con dimensiones psíquicas, reales y afectivas; dando repuesta no solo a lo qué ocurrió, sino también cómo ocurrió, por qué ocurrió y quiénes son los seres humanos que participaron en estos acontecimientos. Esta apuesta conceptual desarrollada por Marc Bloch (1949), Lucien Febvre (1982) y Fernando Braudel (1979) ${ }^{5}$ propende por configurar los hechos históricos, como problema, los cuales son abordados desde la idea de la complejidad social y para su interpretación convocan miradas de diversas disciplinas que desde su saber aportan a la comprensión. Se entiende lo histórico como un proceso complejo, en donde el documento escrito, no es la única fuente de conocimiento, reconoce que cualquier realización que parta de la actividad humana, es fuente para hacer la historia. Este enfoque de la historia nos facilitó abordar el devenir y la construcción de la política educativa para la infancia en medio de tensiones, desplazamientos y rupturas.

El estudio se desarrolló desde la metodología cualitativa documental, que centra la mirada en la producción discursiva de la política, la pedagogía y la educación en

5 Ver Fernando, Braudel, La larga duración en La historia y las ciencias sociales, (Madrid: Alianza Editores, 1979). Lucien, Febvre, Combates por la historia, (España: Editorial Ariel, 1982). Marc Bloch, Introducción a la Historia, (Buenos Aires, Fondo de Cultura Económico, 1982) 
una época determinada; discursos que se encuentran registrados en documentos de política, leyes, normas, planes de desarrollo, planes sectoriales, planes decenales de educación y en los lineamientos curriculares y pedagógicos, entre otros.

Al ser una investigación de corte histórico, se aborda en tres periodos: primer periodo, entre 1982 a 1994, caracterizado por la emergencia y consolidación del Movimiento Pedagógico Colombiano, que es liderado por el sindicato de maestros FECODE ; el segundo periodo, comprendido entre 1994 al 2004, tiempo en el cual se emite la Ley General de Educación (Ley 115/94) y con ello se estructura la reforma educativa desde el Estado, mediante la organización del sistema educativo por niveles, y el tercer periodo comprendido entre el 2004 hasta 2015, caracterizado como un periodo de reforma, especialmente en la ciudad de Bogotá, D.C., cuando a partir del año 2004, un sector representante del magisterio asume la dirección de la Secretaría de Educación y desde allí impulsa una propuesta educativa que tiene como objetivo desarrollar los postulados de la Ley General de Educación, especialmente en el fortalecimiento y defensa de la educación pública, y que hasta el momento estaban aplazados. En este periodo de tiempo nos interesa mostrar las tensiones dadas entre el gobierno central (hegemónico) y la propuesta alternativa de Bogotá.

Así, esta periodización parte de buscar en el pasado, el devenir de las políticas educativas para la infancia, proceso que hunde sus raíces en la reforma educativa de los años 90, discurso desde el cual se ha configurado en gran medida, los currículos, los contenidos, la organización estructural y funcional de la educación, las modalidades de atención y los modelos y las prácticas para la educación de la infancia en la actualidad.

El artículo centra la reflexión, en primer lugar, en las políticas educativas para la infancia y su relevancia en la formación de los sujetos, desde una aproximación a la política educativa respondiendo a la pregunta sobre ¿quiénes son los actores de las políticas educativas y cuáles son los dispositivos pedagógicos y curriculares que se han promulgado para la formación de los niños, niñas y maestros? En segundo lugar, se presenta una aproximación a las continuidades, discontinuidades y tensiones presentes en las propuestas hegemónicas y alternativas de la política educativa para la infancia en Colombia entre 1982 y 2015. Finalmente se presentan a manera de conclusiones generales algunos de los hitos y principales huellas trazadas por el Estado y los grupos sociales que han aportado a la construcción de la política educativa para la infancia.

$6 \quad$ FECODE: Federación Colombiana de Educadores Sindicato que desde 1979, se instaura como un actor político que pretendía impulsar transformaciones en el sistema educativo colombiano, el cual había heredado elementos estructurales como: el alto peso a la educación privada; la segregación socioeconómica marcada entre la educación privada y la pública; la creciente desconfianza del Estado a la labor de los maestros; las discontinuidades y rupturas presentes entre los niveles del sistema educativo; la debilidad de la participación de otros sectores sociales en la educación; la falta de reconocimiento de la visión pedagógica sobre los problemas educativos la cual centraba la educación en la reproducción de métodos de enseñanza y al maestro como un operario del currículo escolar establecido, además de una visión tecnocrática de la educación que se impulsaba en el país a partir de la segunda mitad del siglo XX. 


\section{Las políticas educativas para la infancia y la formación de sujetos}

Las políticas educativas cobran relevancia por su papel en la formación del sujeto, tanto en su desarrollo individual como en la potencialización de sus capacidades sociales. Las políticas educativas, se inscriben en el marco amplio de las políticas públicas, sobre ellas existe mucha literatura, asumimos la siguiente conceptualización por ser coherente con nuestro proyecto:

Las políticas públicas son un factor común de la política y de las decisiones del Gobierno y de la oposición. La política puede ser analizada como la búsqueda de establecer políticas públicas sobre determinados asuntos, o de buscar influir en ellos. A su vez, parte fundamental del quehacer del Gobierno se refiere al diseño, gestión y evaluación de las políticas públicas. Entre los objetivos de los políticos se encuentra el de establecer políticas que impulsen sus compromisos políticos o bloquear aquellas que resulten contrarias a sus objetivos.?

En este marco, la política educativa para la infancia se propone legitimar a niños y niñas como sujetos de derechos y políticas, la política es entendida según Roth ${ }^{8}$, como un conjunto de objetivos colectivos considerados necesarios o deseables para mejorar la calidad de vida de los niños y niñas Colombianos, propósitos que demanda estructurar medios y acciones, con el fin de orientar las prácticas y los discursos de los maestros responsables de la educación de la infancia, a fin de modificar la situación o la realidad percibida como insatisfactoria o problemática.

Desde esta perspectiva, en esta investigación nos preguntamos por ¿Quiénes son los sujetos que han promovido y participado en las políticas educativas? ¿Cómo han sido considerados los niños, las niñas y los maestros en el marco de la legislación y la política educativa en el país? y ¿Qué transformaciones se han producido desde las políticas educativas para la infancia? ¿Quiénes son los niños y niñas beneficiarios de las políticas? ¿Cuál es el imaginario de niño y niña que se proyecta en las políticas educativas para la infancia?

Dar respuesta al interrogante sobre los sujetos de la política educativa para la infancia, así como comprender los sentidos, significados e imaginarios que se ha construido a través del dispositivo político en el país, hace ineludible situar el concepto de sujeto como un sujeto histórico social y de experiencia. ${ }^{9}$

$7 \quad$ Apud. Eugenio Lahera, por Luis Eduardo Pérez Murcia, en, Los Derechos Sociales en Serio: Hacia un diálogo entre derechos y politicas públicas, eds. Luis Eduardo Pérez Murcia, Rodrigo Uprimmy y César Rodríguez Garavito (Bogotá: Centro de Estudios de Derecho, Justicia y Sociedad, Instituto para la Investigación y el desarrollo pedagógico-IDEP, 2007), 77.

8 André-Noël Roth, Políticas Públicas, Formulación e Implementación, (Bogotá: Ediciones Aurora, 2002), 25.

9 En este sentido, para nuestro estudio el ser humano (sujeto) tiene una triple condición es un ente biológico, psíquico y socio histórico, el cual construye un mundo propio a partir de las significaciones imaginarias con las cuales otorga sentido al decir y el hacer en el espacio social. Este proceso de construcción del mundo para sí, es una creación incesante espontánea de formas, imágenes, figuras y representaciones que le permite suplir sus necesidades, incluyendo la supervivencia. (Cornelius Castoriadis, Sujeto y Verdad en mundo histórico social: Seminarios 1986 - 1987, Buenos Aires, Fondo de Cultura Económica de Argentina S.A., 2002). Este proceso de creación, el sujeto lo realiza no solo desde la receptividad de impresiones del mundo (ser afectado pasivamente) sino desde el sentido del "para sí" es decir, "ser afectado, chochado por lo que es fuera de él, a este choque reacciona creando imágenes, representaciones a su propia manera, y esta manera propia es primero y ante todo es representarse algo, ahí en donde en el origen no hay más que choque" (Ibid., p. 76). En este proceso de afectación desde afuera, incluye o considera al "otro" con el que se tejen 
Los sujetos son llamados a realizar transformaciones de sí mismo, de las instituciones, de las prácticas y de lo instituido. Es decir, el sujeto es un sujeto efectivo, en palabras de Castoriadis ${ }^{10}$, es un sujeto con voluntad y autonomía; en donde el camino para transformar, no es el devenir, sino la voluntad, en el que la voluntad de ser y hacer, a partir de su subjetividad reflexiva y deliberante convierte al individuo en sujeto político con voluntad de cambio y cooperación en ámbitos sociales.

Desde esta conceptualización, la infancia es entendida como una categoría histórico social, en tanto hace referencia a los niños y las niñas como sujetos, para quienes en diferentes momentos de la historia hemos construido un mundo social y cultural entre tensiones, continuidades, retrocesos, cambios y transformaciones, en los cuales se ha configurado y reconfigurado la forma de interactuar y entender a los niños, se ha ido particularizando sus contextos en el marco de la mirada de los adultos, se han transformado los imaginarios de los adultos y las condiciones en la vida de ellos como actores de su propio desarrollo, se han reconocido como sujetos sociales, en tanto se han construido entornos y tejidos culturales, políticos y sociales que permiten trascender sus realidades, sus formas de ser y habitar en el mundo.

En Colombia la infancia hace parte de la agenda pública desde 1968, con perspectivas, principios y conceptos que muestran las continuidades y discontinuidades en los discursos, las acciones y las prácticas. Los discursos sobre la política educativa, dan cuenta de la emergencia de un conjunto de ideas, sentidos y significados sobre la infancia, que en clave de tiempo van desde el concepto de minoridad, irregularidad hasta el principio del interés superior del niño y su reconocimiento como sujetos de derecho y como agentes de la política pública ${ }^{11}$.

Como antecedente a la Política Pública de Infancia y Adolescencia, se encuentra la Ley 7 de 1979, con la cual se organiza el Sistema Nacional de Bienestar Familiar (SNBF), se dictan normas para la protección de la niñez, y se reorganiza el Instituto Colombiano de Bienestar Familiar (ICBF). Esta Ley, por primera vez en la legislación colombiana reconoce a los niños y las niñas como sujetos de la política pública

La niñez constituye parte fundamental de toda política para el progreso social y el Estado debe brindar a los niños y a los jóvenes la posibilidad de participar activamente en todas las esferas de la vida social y una formación integral y multifacética [...] todo niño tiene derecho a participar de los programas del Estado y a la formación básica que se brinda a los colombianos, sin distinciones de raza, color de piel, sexo, religión, condición social o procedencia. Del mismo modo tiene derecho a ser educado en espiritu de paz y fraternidad universal ${ }^{12}$.

entramados psíquicos, culturales y sociales que no solo devienen del presente, sino que incorpora el pasado. Así, el sujeto es histórico social y en él se encarnan las instituciones sobre las cuales se instituye la sociedad.

10 Cornelius Castoriadis, Sujeto y Verdad en mundo histórico social: Seminarios 1986 - 1987, (Buenos Aires: Fondo de Cultura Económica de Argentina S.A., 2002) 76.

11 Ver Cecilia Rincón, “Imaginarios de Infancia, políticas públicas y prácticas pedagógicas” (Tesis doctoral en Universidad Nacional Autónoma de México - UNAM, 2013).

12 Ley 7 de 1979: Por la cual se dictan normas para la protección de la Niñez, se establece el Sistema nacional de Bienestar Familiar y se reorganiza el Instituto Colombiano de Bienestar Familiar ICBF. (. República de Colombia, 1979) Artículo 2. 
Durante la década de los 70 las políticas sociales para la infancia, configuraron una significación imaginaria ${ }^{13}$ del niño, como un ser humano carente, vulnerado, necesitado de orientación, protección y cuidado por parte del adulto; esta significación orienta la acción y las propuestas de políticas sociales bajo los principios de asistencialismo y restitución de derecho.

En Colombia como en otros países de América Latina, las políticas sociales no son construidas desde un enfoque de derechos, en nuestro país solo hasta hace muy poco y frente a la complejidad de la situación política y social de Colombia, los decisores de política, han propuesto un discurso que articula la lógica de los derechos humanos, con las lógicas de políticas sociales; al respecto Luis Pérez, César Rodríguez y Rodrigo Uprimny, señalan que:

Pese a ser aliados naturales, los derechos humanos y las políticas públicas han estado distantes por mucho tiempo: En efecto solo, en tiempos recientes estas han sido puestas en primer plano como un valioso instrumento para la prevención, protección y realización de los derechos humanos en general y de los derechos económicos, sociales y culturales en particular ${ }^{14}$.

En cuanto a los derechos de los niños y las niñas, consagrados desde el principio del interés superior del niño, se puede decir que en nuestro país las políticas educativas para la infancia, son el complemento para que la sociedad y la jurisprudencia garanticen el cumplimiento de los derechos orientados a la protección, el cuidado y la educación, pero a su vez "los derechos humanos establecen límites normativos para la elaboración y aplicación de las políticas públicas en la democracia constitucional"15, configurándose así una articulación discursiva y práctica que instaura nuevas formas de afrontar las realidades de los niños, iniciativas que se tejen entre las tensiones de lo hegemónico y lo alternativo. Podemos decir, que es en el intersticio que deja el no cumplimiento de los derechos de los niños por parte del Estado, el espacio en el que emergen las propuestas alternativas desde la sociedad civil para la reformulación y transformación de las políticas sociales.

\section{Niños y niñas sujetos de derecho en el marco de la política educativa}

En Colombia, en la década de los 80 y 90, se configura una gran apuesta por la educación, se inicia una verdadera transformación de la política educativa, se formulan programas y proyectos que determinan el acontecer en materia de educación de la infancia, de los niños y las niñas como sujetos pedagógicos y políticos. En este período la educación vivió una revolución, se inició una transición en la que se

13 Ver Cornelius Castoriadis, La institución Imaginaria de la sociedad, (Argentina: Fábula Tusquets Editores, 2013), 529- 579. Y Cecilia Rincón, et al., Imaginarios de infancia y la formación de maestros, (Bogotá: Editorial Magisterio, 2008).

14 Luis E. Pérez, César Rodríguez y Rodrigo Uprimny, Los derechos sociales en serio: hacia un diálogo entre derechos y políticas públicas, (Bogotá: IDEP, Ediciones Antropos, 2007), 17.

15 Ibíd. 
realizaron cambios a nivel de la estructura y la funcionalidad del Sistema Educativo. Estas transformaciones incluyeron la organización de la educación preescolar que venía dando respuesta a un paradigma asistencialista en relación con la idea de cuidar, proteger a los niños y niñas más vulnerados en los jardines de atención del Instituto Colombiano de Bienestar Familiar (ICBF).

Sin embargo, frente a la proliferación de los jardines infantiles privados y a las nuevas necesidades de aprendizaje de los niños, surge la preocupación de los expertos y padres de familia por el desarrollo infantil; como lo relata Absalón Jiménez ${ }^{16}$, al comienzo de los años ochenta los programas de educación infantil se habían convertido en una preocupación de los gobiernos, de manera que se dio el paso del "paradigma de beneficencia y asistencialismo social" delos años setenta al "paradigma del desarrollo infantil". Esta variación en el discurso de las políticas, no aseguró la transformación y modificación del paradigma asistencialista que en Colombia tiene ya una larga tradición y pese a los desarrollos, en la actualidad se continúan formulando políticas sociales con estos matices. No obstante, sí se constituyó en un período en el que se gestaron nuevas formas de concebir a la infancia en el marco de la política pública, aunque tardaría algunas décadas para que se transcendiera de los discursos de las políticas y disposiciones legales a la transformación de las realidades de los niños y niñas colombianos.

Es en este contexto que Colombia inicia una reforma legislativa a partir de la década de los ochenta, en la que afloraron posturas e imaginarios instituyentes sobre las formas de reconocer y considerar a los niños y las niñas en el marco de las políticas y el cumplimiento de sus derechos. Estas transformaciones se consolidan en la cultura política a partir de 1991, con la Ley 12 de 1991 por medio de la cual Colombia ratifica los postulados de la Convención Internacional de los Derechos del Niño (1989).

En este mismo año se aprueba por medio de la acción del plebiscito, la nueva Constitución de Colombia 1991, la cual es producto de un debate y de la más grande convocatoria a la participación ciudadana que se haya dado en nuestra historia a través de la Asamblea Nacional Constituyente, en ella participaron representantes de todos los sectores de la sociedad, incluyendo a los maestros a partir de su organización en el Movimiento Pedagógico. Posteriormente en el campo de la educación, en este marco de reformas legislativas en Colombia, se aprueba en el año 1994, la Ley General de Educación ${ }^{17}$ con la cual se organiza el Sistema Educativo de Colombia, tanto en la definición de la educación como un servicio y como un derecho, así como en sus fines, su estructura y las especificidades entorno a la prestación del servicio. A partir de este momento la ley 115 Ley General de Educación ${ }^{18}$ orienta la política educativa en el

16 Absalón Jiménez, Emergencia de la infancia contemporánea 1968-2006, (Bogotá: Universidad Francisco José de Caldas, 2012 ), 165.

17 Ley 115: Ley general de Educación, (República de Colombia: Febrero 8 de 1994)

18 La ley 115 de 1994 hunde sus raíces en el Movimiento Pedagógico fundado por Fecode en 1982, aunque vista como una experiencia de concertación entre el gobierno y Fecode, sus antecedentes bien pueden remontarse a la negociación del Estatuto Docente de 1979, expedido mediante el decreto Ley 2277 de ese año. Sus Fundamentos y propósitos se encuentran en la Constitución Política de 1991. [...] la nueva situación creada por la expedición del Estatuto Docente fue aprovechada por la dirigencia gremial para pensar el Movimiento Pedagógico, que al final comprendió los nuevos asuntos de los que debía ocuparse la organización sindical, los asuntos propios del oficio de los maestros y de su campo de trabajo, la educación. El Movimiento Pedagógico [...] fue una respuesta de los educadores organizados a la pretensión gubernamental de imponer desde arriba y sin ninguna participación de la comunidad educativa, un currículo "aprueba de maestros" [...] en efecto, el hecho concreto, el florero, que motivo e impulso la 
país y se constituye en el marco de referencia para la formulación de los programas y proyectos de la política educativa para la infancia.

La construcción y promulgación de La Ley General de Educación (ley115 de 1994) marca un hito para la política educativa, en tanto desde sus postulados se configura no solo como una legislación, sino como una política pública; esta ley pone a la educación en la esfera de lo político y a la política en el marco de la formación de los ciudadanos, por cuanto va configurando un nuevo sentido a la educación, a los sujetos educativos, al papel de la pedagogía y a la organización misma del sistema educativo. Esta ley define la educación como "un proceso de formación permanente, personal, cultural y social que se fundamenta en una concepción integral de la persona humana, de su dignidad, de sus derechos y de sus deberes"19

Seorganizaron losniveles del sistema educativo en Colombia: educación preescolar, educación básica primaria y básica secundaria y educación media. En esta estructura se estableció la educación preescolar como obligatoria mínimo de un grado en la educación oficial, y se definió como: “La educación preescolar correspondea la ofrecida al niño para su desarrollo integral en los aspectos biológico, cognoscitivo, sicomotriz, socio-afectivo y espiritual, a través de experiencias de socialización pedagógicas y recreativas ${ }^{\prime 20}$. En esta política educativa, se logra dilucidar una perspectiva de niño y niña que buscaba movilizar la idea de un niño pasivo y receptivo, a una visión del niño como un ser integral y sujeto de derechos.

El haber incorporadoenla Ley, la obligatoriedad al menos de un grado de preescolar en la educación pública, produjo varios efectos, primero en cuanto a la masificación de las ideas sobre el desarrollo infantil, las teorías del desarrollo y la formación integral del niño, en segundo lugar hay nuevas exigencias para el sujeto maestro, en cuanto a su formación como Licenciados o expertos en preescolar o educación inicial; los maestros ahora, deben partir del juego como el principal pilar de la enseñanza y del desarrollo de la mente infantil, dando así un giro en las prácticas pedagógicas, quienes trabajan en el marco de una enseñanza memorística e instrumental.

Los objetivos del nivel de preescolar en la Ley 115 de 1994, son otro factor que apuntalan a posturas alternativas frente al concepto del niño, ya que en su discurso promueve un cambio pasar del concepto del niño como alumno, al concepto del niño como sujeto activo y eje de la acción pedagógica:

“a) El conocimiento del propio cuerpo y de sus posibilidades de acción, así como la adquisición de su identidad y autonomía; [...] b) El desarrollo de la creatividad, las

creación del Movimiento Pedagógico fue la reforma curricular que el Ministerio de Educación lanzó a finales de los setenta bajo la forma de experimentación curricular. [...] La reforma educativa introducida por la Ley General no fue fortuita. Sin proponérselo expresamente, el Movimiento Pedagógico había preparado al magisterio para participar en el proceso constituyente del 91, dotándolo de una herramienta valiosísima: la iniciativa de la reforma de la educación y la enseñanza, aprobada por los participantes en el Congreso Pedagógico de 1987. De aquí la claridad de propósitos y metas que sus voceros presentaron y defendieron en la Asamblea Nacional Constituyente. (Abel Rodríguez, 20 años de la Ley General de Educación: resultados y Posibilidades, Bogotá, Editorial Magisterio, 2015, pp. 27 - 35). También se considera que el antecedente jurídico y político de la Ley General de Educación es la Constitución Política de 1991, en tanto los cambios o la reforma educativa propuesta en la Ley tienen el sustento jurídico de la Carta Magna y se proponen con el fin de reglamentar y dar alcance a los mandatos en materia de educación.

19 Ibid, p. 1

20 República de Colombia, op. cit., Articulo 15, p. 5 
habilidades y destrezas propias de la edad, como también de su capacidad de aprendizaje, $[\ldots]$ d) relaciones de reciprocidad y participación, de acuerdo con normas de respeto, solidaridad y convivencia; [...]; g) El estímulo a la curiosidad para observar y explorar el medio natural, familiar y social; [... i) La vinculación de la familia y la comunidad al proceso educativo para mejorar la calidad de vida de los niños en su medio [...]. ${ }^{21}$

El conocimiento del propio cuerpo, la construcción de identidad y autonomía, el crecimiento equilibrado, el desarrollo motriz, el desarrollo de la creatividad, la motivación y aprestamiento en lectoescritura y matemáticas, el reconocimiento de formas de expresión, relación y comunicación, la participación, la curiosidad y la vinculación de la familia entre otros, se convierten en postulados alternativos que buscaban ser asumidos y posicionados en los contextos escolares, hallando así el sentido del preescolar, ya no como cuidado y guardería sino como preparación para la vida.

En este sentido, podemos afirmar que la Constitución Política de 1991 y la Ley General de Educación, crearon un nuevo derrotero en el campo de la política educativa y los derechos de los niños, donde sus alcances en cuanto a la formación democrática y la autonomía no tiene precedentes en el país. Así, la Ley General de Educación da cumplimiento a lo consagrado en la Convención de los Derechos del Niño (1989), garantizando que el contexto físico y social permita el pleno desarrollo y la formación integral de la infancia en marco de la participación ciudadana, lo cual aproxima la política y la legislación a formas y prácticas más claras para entender lo que significa ser niños y niñas y define acciones concretas para su educación, cuidado y protección, con primacía del interés superior del niño y lo constituye como sujeto de derechos y sujeto de políticas.

En síntesis, este periodo en la historia de política educativa para la infancia, permitió aproximarse a nuevas concepciones del sujeto niño que proponían formas alternativas de relacionarse con ellos y de articular las políticas con los derechos, lo cual implicó nuevas exigencias para el Estado desde sus dispositivos jurídicos y administrativos. Sin embargo, en el trascurso de los años 90 y comienzos del siglo XXI, estas propuestas encarnadas en la legislación se convierten en propuestas en ocasiones aisladas, pausadas y hegemónicas en la medida en que se asumen desde el Estado con discursos totalizantes desconociendo la particularidad de los contextos y las realidades de la infancia.

En la actualidad estas políticas no han logrado consolidarse como el horizonte para transformar la realidad de las prácticas pedagógicas, tampoco han logrado superar las brechas de inequidad y acceso a la educación preescolar; como se observa cuando, mientras en la educación privada los niños acceden a tres grados de preescolar, en la educación oficial los niños tienen derecho solo a un grado de educación preescolar. Así mismo, la destinación de los recursos para la educación de la infancia son bajos, su distribución responde a un enfoque de política poblacional y no logra consolidar

21 República de Colombia, op. cit., Articulo 16, p. 5 
estrategias más rentables y alternativas que permitan cumplir con la materialización del derecho a la educación con calidad y con las perspectivas del desarrollo infantil.

\section{Lo que antes era un deseo ahora es una realidad: Bogotá y la materialización del derecho a la educación inicial.}

En Bogotá, hoy hablar de educación inicial, es volver la mirada a los significativos avances logrados desde hace más de doce años. Es así como el Plan de Desarrollo Bogotá Sin Indiferencia 2004 a 2008, inscribió la Política de Infancia de Bogotá 2004-2015: Por la calidad de Vida de los niños, niñas y adolescentes"22, bajo las recomendaciones de la Convención Internacional de los Derechos del niño, ratificada por Colombia mediante la Ley 12 de 1991, en la Constitución Política y en los demás tratados y convenios internacionales relacionados con la infancia. Es importante destacar que esta política de Bogotá, se constituyó en el principal referente para el resto del país en materia de política de infancia y podemos decir que es la antecesora de la "política de Estado para el Desarrollo Integral de la Primera Infancia de Cero a Siempre, Ley 1804 del 2 de agosto del 2016" que recientemente se acaba de aprobar.

El aporte fundamental de la Política de Infancia de Bogotá 2004 - 2015: Por la calidad de Vida de los niños, niñas y adolescentes consistió tomar en cuenta la condición de irregularidad y vulnerabilidad en la que vivían los niños y las niñas de la ciudad, para afrontar esta situación estableció los siguientes ejes de política: La protección de la vida; el inicio de una vida digna; una ciudad segura; seguridad alimentaria; generación de escenarios propicios para el desarrollo; relaciones propicias para el desarrollo; ambiente amigo de los niños, las niñas y los adolescentes; niños y niñas a la escuela, adultos-as al trabajo; condiciones para el ejercicio de la ciudadanía; actores de sus propios derechos y educación inicial como un derecho impostergable.

La Política de Infancia y Adolescencia del Distrito Capital, entendió la infancia en un sentido complejo como:

Un momento de la vida particularmente importante, en la que se sientan las bases de nuestras potencialidades y capacidades; de las oportunidades que tengamos durante nuestra vida de niños y niñas depende en gran parte que estas se desarrollen y consoliden. Tener una familia que nos acoja, nos proteja y crea en nosotros y nosotras, [...] ser respetados y respetadas en cada uno de los lugares en los que transcurre nuestra vida, sentirnos segurosas y queridos-as; son condiciones mínimas para que la vida de todos los seres humanos inicie y curse de manera feliz $[\ldots]^{23}$.

En esta política, se avanzó en el reconocimiento de los niños y niñas como sujetos de derecho, partícipes de las decisiones de sus vidas; nos podemos arriesgar, a decir que, se supera la visión del niño en situación de irregularidad, pero además la intención asistencialista de la política en tanto la garantía del cuidado, la educación y

\footnotetext{
22 Alcaldía Mayor de Bogotá, Quiéreme bien, quiéreme hoy Política por la calidad de vida de niños, niñas y adolescentes en Bogotá, 2004 - 2008, (Bogotá: 2004).

23 Ibíd., p. 5
} 
la protección están unidos a empoderar a los niños, niñas y jóvenes como agentes de política, partiendo de su desarrollo personal, integral y diferente.

Este discurso político sobre la infancia irrumpe en la ciudad y en el país, como una alternativa, frente a la grave condición de vida de nuestros niños y niñas, buscando hacer de Bogotá una sociedad más justa, equitativa e incluyente, que reconozca y propicie las condiciones materiales y afectivas para garantizar el ejercicio pleno de los derechos. Así mismo, la Política Educativa de Bogotá, desarrolla una postura social a favor de la reivindicación de la educación como derecho de la infancia, centrando su mirada en la educación inicial. Es un discurso de política instituyente y de acciones alternativas, que tiene su origen en el conocimiento de la educación y la infancia de líderes sindicales, pedagogos y maestros, que en su momento hicieron parte e impulsaron el Movimiento Pedagógico Colombiano.

En este marco, existió la Red de Jardines Sociales del Distrito en el 2007, la cual sirvió para atender a las comunidades en condición de alta vulnerabilidad. También se desarrolló el Código de Infancia y Adolescencia del 2006, de donde se plantea de manera específica el concepto de primera infancia, definición que permite comprender el alcance en la atención a la niñez desde la corresponsabilidad y de manera integral:

La primera infancia es la etapa del ciclo vital en la que se establecen las bases para el desarrollo cognitivo, emocional y social del ser humano. Comprende la franja poblacional que va desde los cero (0) a los seis (6) años de edad. Desde la primera infancia, los niños y las niñas son sujetos titulares de los derechos reconocidos en los tratados internacionales, en la Constitución política y en este Código. Son derechos impostergables de la primera infancia, la atención en salud y nutrición, el esquema completo de vacunación, la protección contra los peligros físicos y la educación inicial. ${ }^{24}$

Con este periodo, se avanza al logro de mejorar la calidad de vida de los niños, niñas y adolescentes de la ciudad; dicha política distrital, fue un compromiso social de luchar en contra de la violencia y la exclusión, se realizaron intervenciones integrales, interinstitucionales e intersectoriales para enfrentar los problemas. En este marco del Plan de Desarrollo Distrital, es importante señalar el carácter de intersectorialidad que plantea, la posibilidad de un trabajo mancomunado superando la mirada exclusiva de sectorialidad y llegando a un conjunto de acciones en favor de atenciones dirigidas a la niñez de la ciudad.

Otros dos aportes a reconocer del "Plan de Desarrollo Bogotá Positiva", es uno que hace referencia a la intencionalidad de mejorar la calidad de vida de niños, niñas y adolescentes y otro que refiere a la comprensión y adaptación del concepto de desarrollo humano desde los primeros años de vida, de cara al desarrollo social de la ciudad, que mitigue la desigualdad y la exclusión social.

De esta forma la Política Educativa de Bogotá, durante los últimos doce años, se convierte en una propuesta alternativa que busca responder al anhelo de defender la educación pública, el derecho a la educación con calidad, hacerla incluyente,

24 Ley 1098: Código de la Infancia y la Adolescencia, (República de Colombia, 2006) Artículo 29. 
participativa, diferencial y convertirla en una herramienta efectiva para la vida y para superar las brechas de la inequidad social. Esta experiencia de la Política Educativa de Bogotá, parte de lo institucional y se encarna en la entidades y organizaciones como la Secretaría de Educación y la Secretaría de Integración Social, para resignificar los saberes de los sujetos, empoderarlos, promover nuevos planteamientos e impactar la realidad educativa de la ciudad.

Como se ha señalado, la política de Bogotá se convierte en el referente para la formulación de la "política de Estado para El Desarrollo Integral de la Primera Infancia de Cero a Siempre, Ley 1804 del 2 de agosto del 2016"25 que enuncia como objetivo principal el desarrollo integral de la primera infancia, sus programas, estrategias y acciones se orientan desde los conceptos fundamentales de reconocer a los niños como sujetos de derecho y su protección integral ${ }^{26}$, instaurando como horizonte de la acción política no solo a los niños, sino a los sectores políticos, sociales, económicos y a la sociedad en general, como lo enuncia en la introducción del documento:

La Estrategia para la Atención Integral de la Primera Infancia se ha construido, [...] poniendo en el centro a las mujeres gestantes y a las niñas y los niños desde su nacimiento hasta los seis años de edad. Concebirlos como sujetos de derecho, únicos y singulares, activos en su propio desarrollo, interlocutores válidos, integrales, y reconocer al Estado, la familia y la sociedad como garantes de sus derechos. [...] es un imperativo ético, un propósito vital de nación que no parte de la nada, que reconoce los caminos transitados por el país en favor de una política pública para la primera infancia, que ha convocado a diversos sectores de la sociedad para recoger y debatir ideas, para contrastar posturas y experiencias, para llegar a acuerdos. [...] para que el país actúe de manera sintonizada en favor del desarrollo integral de la primera infancia ${ }^{27}$.

La Política de Cero a Siempre toma como eje la atención integral de la niñez y hace al Estado Colombiano el responsable de construir las estrategias para superar las brechas que han marcado el desarrollo de la infancia en nuestro país y que han determinado sus condiciones de vida. Busca además la garantía de los derechos a partir de ampliar las posibilidades de acceso y permanencia en el sistema educativo de los niños y niñas de los estratos 1, 2 y 3, de las etnias y la población en condición de pobreza.

Si bien esta política fue aprobada en el 2016, su desarrollo y su implementación aún es incipiente y enfrenta grandes retos como los siguientes: constituirse en una

25 Presidencia de la República de Colombia, Estrategia de atención integral a la primera infancia: fundamentos políticos, técnicos y de gestión, (Bogotá: Imprenta Nacional, 2013)

26 La hoy política nacional de Cero A. Siempre, inicialmente fue una estrategia de atención a la primera infancia formulada en el primer gobierno del Presidente Santos $(2010$ - 2014). En donde se desarrolla la conformación de una instancia articuladora y coordinadora de la atención integral para la infancia la cual fue incluida como prioridad en el "Plan Nacional de Desarrollo 2010-2014: Prosperidad para Todos". En ella el gobierno se comprometió con el diseño y puesta en marcha de una estrategia que involucrara la acción decidida de los sectores de gobierno, planeación, salud, educación, cultura y bienestar, estableciendo metas e inversiones específicas para la primera infancia, que apoyadas en desarrollo legales y técnicos complementarios, apostaron a que la atención integral a la primera infancia fuera una acción permanente y sostenible del Estado. Es así como en el segundo gobierno del Presidente Santos, pasa de ser una estrategia a convertirse en Política Nacional.

27 Presidencia de la República de Colombia, op. cit., p. 17 
política de largo plazo capaz de orientar al país en materia de sostenibilidad técnica y financiera; universalización dela atención y fortalecimiento delos territorios; garantizar la pertinencia y la calidad en la atención integral a la primera infancia articulando acciones desde antes de la concepción hasta la transición hacia la educación formal, así como sensibilizar y movilizar a toda la sociedad colombiana para transformar las concepciones e imaginarios y las formas de relación con los niños y las niñas y superar el paradigma de la política asistencialista que ha hecho curso en Colombia y en los países de la región.

\section{Los lineamientos pedagógicos y curriculares: dispositivos para la construcción de sujetos niños y maestros en el marco de las políticas educativas}

Como se ha venido enunciando, las políticas públicas son una herramienta para que el Estado cumpla con la garantía de los derechos humanos, en especial los derechos de los niños y las niñas. En este sentido y específicamente en la política educativa, para que estas sean efectivas y permitan avanzar en las obligaciones que sobre educación para la infancia se tienen, en Colombia se consideró necesario desde 1994, construir documentos que llegarán a los actores encargados de concretar las políticas educativas en el marco de las instituciones y la sociedad en general.

Así se crean los lineamientos curriculares, pedagógicos y los estándares ${ }^{28} l o s$ cuales definen desde sus enunciados los sujetos niños y los sujetos maestros, sus funciones y obligaciones para llevar a cabo los objetivos y principios de la política. En este sentido, emerge la noción de sujeto pedagógico, en tanto, el maestro "[...] condensa expectativas y experiencias y es capaz de vislumbrar proyectos en contextos en los que se producen, circulan, transmiten y legitiman saberes. La educación es una práctica formadora y transformadora de los sujetos, cuyo potencial social y cultural se expresa en proyectos sociales ${ }^{29}$.

Desdeestaidea desujeto pedagógico, en los diferentes documentos quese producen en el marco de la política educativa en Colombia después de la Reforma constitucional de 1991, y de la promulgación de la Ley General de Educación, y del Movimiento Pedagógico se resalta el quehacer de los maestros, en cuanto a la formación de niños y niñas y se propone el desarrollo de experiencias pedagógicas innovadoras, en donde se identifica al sujeto maestro y a los niños y niñas como sujetos de derecho.

En el documento Lineamientos Generales de Procesos Curriculares. Hacia la Construcción de Comunidades Educativas Autónomas ${ }^{30}$, se enuncia al sujeto maestro como aquel que es capaz de asumir retos, que participa de agremiaciones sindicales y que puede organizarse para producir conocimiento.

28 Los lineamientos pedagógicos y curriculares, así como los Estándares de la educación, son documentos que determinan los contenidos curriculares, los aprendizajes y las formas de evaluación en las instituciones educativas. Están dirigidos a ser apropiados y desarrollados por los maestros en el aula de clase, convirtiéndose en orientadores o diseñadores de la práctica y la acción pedagógica.

29 Ana María del Pilar Martínez, Prólogo: un recorrido de la obra a través de su proceso de construcción, en Reconfiguración de lo educativo en América Latina: experiencias Pedagógicas alternativas, eds. Marcela Gómez Sollano, et. al. (México: Universidad Nacional Autónoma de México, 2013) 47.

30 Ministerio de Educación Nacional, Lineamientos generales de procesos curriculares para la construcción de comunidades educativas autónomas, (Bogotá: Imprenta Nacional, 1994) 
Por iniciativa de los educadores y las educadoras también se han generado procesos sociales (...) Un ejemplo significativo es el Movimiento Pedagógico promovido por grupos de maestros y maestras, que con gran sentido de responsabilidad y profesionalismo se han dedicado a la investigación pedagógica con todo lo que ello implica de elaboración teórica y búsqueda de horizontes propios ${ }^{31}$.

Una mirada que recoge la consideración del Movimiento Pedagógico, del maestro como intelectual, sujeto de saber y de transformación, y los invita a comprometerse con el liderazgo en el desarrollo de innovaciones educativas y pedagógicas de tal forma que atiendan a las necesidades como profesional y del contexto de los niños y las niñas para realizar el cambio en la educación que el país necesita.

En el marco de la historia de la educación en Colombia, y en el contexto de la Política Educativa a partir de la Ley General de Educación que busca organizar el sistema educativo en 1996, se promulga la Resolución 2343, "por la cual se adopta un diseño de lineamientos generales de los procesos curriculares del servicio público educativo y se establecen los indicadores de logros curriculares para la educación formal" 32 , en la que se reconoce al sujeto niño y niña como aquel que es capaz de aprender en contextos diferentes a su escuela.

La organización de actividades formativas, culturales, recreativas y deportivas deberá atender, de manera general, el desarrollo del sentido de la capacidad lúdica natural del educando que debe impactar el uso creativo y satisfactorio de su tiempo, todas las dimensiones de su desarrollo y su desempeño. En particular atenderá los intereses y necesidades de los estudiantes, destinando para tales efectos espacios $y$ tiempos específicos dentro de la jornada y el calendario académico o fuera de ellos, con la orientación familiar, colectiva y social. .3 $^{33}$

Igualmente, por estos años, que podemos decir, son la imposición y contrarreforma de la educación, propuesta por la Ley General de Educación, se construye los Lineamientos Curriculares para el Preescolar ${ }^{34}$, documento en el cual el concepto de sujeto niño y niña se basa en el desarrollo de sus dimensiones, en una visión de desarrollo integral y como sujetos de derecho

Los lineamientos pedagógicos para el nivel de educación preescolar se construyen a partir de una concepción sobre los niños y las niñas como sujetos protagónicos de los procesos de carácter pedagógico y de gestión. Igualmente se debe tener en cuenta en su elaboración, una visión integral de todas sus dimensiones de desarrollo: ética, estética, corporal, cognitiva, comunicativa, socio-afectiva y espiritual. En tal sentido, los núcleos temáticos que se proponen, pretenden construir una visión de la infancia en donde los niños y las niñas sean considerados como sujetos plenos de derechos cuyo

31 Ibid., p. 21

32 Resolución 2343 de junio 5 de 1996, (República de Colombia: Ministerio de Educación Nacional, 1996)

33 Ibíd., p. 15

34 Ministerio de Educación Nacional, Lineamientos Curriculares. Preescolar, (Bogotá: Ministerio de Educación Nacional,1998) 
eje fundamental sea el ejercicio de los mismos y una educación preescolar acorde con estos ${ }^{35}$

En el año 2009, el Ministerio de Educación Nacional, presenta la Guía operativa para la prestación del servicio de atención integral a la primera infancia ${ }^{36}$, propone tratar al sujeto niño - niña como un sujeto con capacidades, competencias, capaz de proponer, resolver y actuar en diferentes situaciones cotidianas.

El nuevo concepto de niño y niña reconoce que: Nacen con las capacidades para establecer relaciones sociales y con el mundo físico y natural que les rodea...Pueden caminar, coordinar los movimientos del cuerpo y producir lenguaje, entre otras conductas que satisfacen sus necesidades respondiendo a las demandas del contexto. Se relacionan con el entorno al proponer, resolver y actuar en las distintas situaciones de su vida cotidiana. ${ }^{37}$

En síntesis, podemos decir que, en los documentos de los lineamientos curriculares y pedagógicos, se puede identificar que el concepto que se tenía sobre el sujeto maestro, era el de líder y el de pedagogo, un sujeto capaz de transformar, de proponer y de llevar a cabo reformas. Una idea instituyente que contradice el objeto mismo de estos documentos, en tanto los lineamientos pedagógicos y curriculares determinan los contenidos a enseñar y orientan las prácticas y las acciones pedagógicas en el aula de clase, volviendo nuevamente al maestro en un ejecutor de un currículo establecido desde la hegemonía del Ministerio de Educación Nacional, tanto así, que en la actualidad el sujeto maestro, ahora se nombra como un "Agente educativo", es decir uno más de los adultos cuidadores que desarrollan las política de infancia.

Así mismo, el sujeto niño y niña también se ha transformado convirtiéndose en el centro de nuevas miradas, hasta el punto de reconocerlo como un sujeto de derechos y sujeto de política, capaz de participar en la construcción de su conocimiento, es un sujeto con agencia, participativo y democrático, dejando de ser solo un sujeto de derecho.

\section{Hegemonía y alternativas: tensiones, continuidades y discontinuidades en la Política Educativa para la Infancia}

Reflexionar sobre la hegemonía, nos obliga a pensar necesariamente en su opuesto que es lo alternativo, para $\mathrm{Laclau}^{38}$, estas categorías, son articulaciones

35 Ministerio de Educación Nacional, op. cit., p. 3

36 Ministerio de Educación Nacional, Guía operativa para la prestación del servicio de atención integral a la primera infancia. Guía 35, (Bogotá: Imprenta Nacional, 2009)

37 Ibid., p. 13

38 Ernesto Laclau y Chantal Mouffe, Hegemonía y Estrategia socialista. Hacia la radicalización de la democracia, (Buenos Aires: Fondo de Cultura Económica, 2004) 
discursivas de un sujeto que está inmerso en la hegemonía y que no es un sujeto pasivo, es un sujeto activo. La hegemonía es necesaria, no es negativa, en tanto es una forma de organización y depende de si esa organización es momentánea o permanente; los discursos hegemónicos tienen más o menos validez según el momento histórico en el que se desarrollen como propuesta política e ideológica por su capacidad de unidad y cohesión.

En este proyecto lo hegemónico es un eje de análisis, una noción y una lógica de pensamiento compleja, por ser histórica, dinámica, cambiante y contingente. Para este estudio, es importante asumir la definición de Gramsci ${ }^{39}$, en tanto la hegemonía abarca no solo las formas económicas y políticas, sino que además trasciende las prácticas sociales, las formas de pensar, actuar y de conocer, es decir, es la capacidad que tiene un grupo social en el poder de sumar a sus intereses las voluntades de los demás grupos, imponiendo así su ideología, su ética, sus formas de ver el mundo, sus prácticas y sus constructos culturales. Construyendo de esta forma un aparato hegemónico a través de las instituciones sociales como son la escuela, la iglesia, los medios de comunicación, entre otros, con los cuales se configura una conciencia producto de un proceso social. En este sentido, lo hegemónico no solo se trata del grupo social dominador, sino de esas relaciones que se establecen entre ellos y las clases subordinadas a partir de los vínculos de poder entre el consentimiento y la dominación, lo que lleva a la legitimación bien sea por la fuerza o el consenso de la ideología hegemónica.

En los discursos y los documentos de política educativa colombiana, lo hegemónico y lo alternativo se entrecruzan entre las huellas del pasado y el presente de la educación, estableciendo articulaciones discursivas y prácticas, que permiten identificar los elementos que caracterizan lo hegemónico de la política educativa y las propuestas alternativas que han surgido en el país.

- Un elemento de la política educativa, que se presenta como hegemónico, es la consideración de la educación como medio principal para disminuir la pobreza y alcanzar la equidad social. En este sentido, los diferentes Planes Sectoriales de Educación, hacen alusión a este objetivo de la educación, siendo una constante en el discurso de la política pública. Un ejemplo de ello, es el Plan de Sectorial de Educación "Bogotá una Gran Escuela 2004-2008" que "contempla programas y proyectos encaminados a combatir la pobreza desde la educación, asegurar el acceso al sistema educativo de niñas, niños y jóvenes en el sistema educativo" ${ }^{40}$, con lo que se proponía crear condiciones para "el ejercicio pleno del derecho a la educación, con el fin de mejorar la calidad de vida, reducir la pobreza y la inequidad, potenciar el desarrollo autónomo, solidario y corresponsable de todas y todos los habitantes de la ciudad" ${ }^{\prime 1}$ Desde esta idea la educación ha sido entendía como la llave maestra para superar la

\footnotetext{
39 Antonio Gramsci, El materialismo histórico y la filosofía de Benedetto Croce, (México: Juan Pablos Editor, 1975)

40 Alcaldía Mayor de Bogotá, D.C., Plan Sectorial de Educación 2004 - 2008, Bogotá: una gran escuela para que los niños, niñas y jóvenes aprendan más y mejor, (Bogotá: Secretaría de Educación Distrital, 2004), 10.

41 Ibid., p. 13
} 
pobreza y la inequidad social.

- Otro elemento que marca la presencia de propuestas hegemónicas es el que hace referencia al discurso de la calidad de la educación, desde los criterios de eficiencia y eficacia; donde los resultados de la educación son medidos por pruebas estandarizadas que desconocen las particularidades del territorio nacional. Esta propuesta Estatal asume la educación como un servicio público y no como un derecho para todos y todas y las somete a las lógicas neoliberales.

En los intersticios de lo hegemónico de la política educativa para la infancia, aparecen los discursos alternativos que surgen como respuesta a una problemática. Así, Lo alternativo en el campo social y pedagógico, es una experiencia individual y colectiva que aporta a la construcción de un nuevo proyecto cultural y educativo. De otra parte, las alternativas pedagógicas se inscriben desde la teoría de la resistencia y del conflicto. Lo alternativo no puede concebirse fuera de lo hegemónico, tiene como referente lo institucionalizado y puede surgir en el marco de las propias organizaciones o al margen de las mismas; se expresa a través de las expectativas y experiencias de los sujetos que reelaboran los saberes, producen, circulan y transmiten nuevas ideas que impactan de una u otra manera la realidad. De ahí que los sujetos generen procesos alternativos que se articulan en la sociedad con prácticas y saberes orientando transformaciones que de alguna forma marcan límites a lo instituido y lo reconfiguran ${ }^{42}$. A continuación se enuncian las propuestas alternativas que emergen en este análisis:

- En Bogotá, durante el periodo 2008 a 2012, en el Plan Sectorial de Educación "Educación de calidad para una Bogotá Positiva" se reconfigura el sentido de la calidad educativa promoviendo la idea que el "desarrollo de la educación se inscribe en las políticas generales de la ciudad cuyos propósitos se han orientado a consolidar la democracia, a reducir la pobreza y a mejorar la calidad de vida de sus habitantes" 43 , de esta forma se establece la educación no solo como medio para reducir la pobreza, sino que se requiere de una educación de calidad para contribuir a la equidad social, en tanto se considera que:

En sociedades con profundas e históricas inequidades sociales, la calidad educativa constituye una condición para mejorar las oportunidades, para lograr una inserción plena en la vida social y productiva, a la vez que contribuye de manera indiscutible al desarrollo de la sociedad en su conjunto. Hay que señalar que el aporte de la educación de calidad para el logro de la equidad social no solo se refiere a la superación de condiciones de pobreza y a la ruptura de sus círculos de reproducción, también

42 Ernesto Laclau y Chantal Mouffe, op.cit. p. 13

43 Alcaldía Mayor de Bogotá, D.C., Plan Sectorial de Educación 2008 - 2012: educación de calidad para una Bogotá Positiva, (Bogotá: Secretaría de Educación Distrital, 2008), 9. 
contribuye a la superación de las diferentes formas de exclusión dadas por la condición de género, étnica, discapacidad u otra situación particular. ${ }^{44}$

Esta idea de calidad de la educación, emerge como una alternativa, en tanto considera que la calidad de la educación no puede estar determinada solo por los resultados de unas pruebas ajenas a los contextos reales de la escuela y las condiciones sociales de la población, sino que garantizar y mejorar la de calidad de la educación, como lo enunciaba el profesor Abel Rodríguez Céspedes ${ }^{45}$, convoca necesariamente la necesidad de mejorar las condiciones materiales y pedagógicas de las instituciones educativas, a fin de garantizar el pleno derecho a la educación, asegurar el acceso, la permanencia y la disponibilidad de los recursos que permitan a los niños y niñas, a los jóvenes y adultos una formación para la vida. ${ }^{46}$

La calidad de la educación depende, entre otros factores, de las posibilidades organizativas, técnicas y didácticas, cognoscitivas y pedagógicas desarrolladas en los colegios, así como de la voluntad política del Estado, los educadores, la familia, los educandos y las comunidades. [...] la calidad de la educación comprende dos elementos: uno, el de las condiciones y recursos materiales y dos el de las condiciones pedagógicas que tienen que ver con los contenidos y los métodos de enseñanza, la organización escolar, los espacios y los tiempos escolares, los ambientes de aprendizaje y enseñanza. ${ }^{47}$

Es en este sentido que la propuesta de política educativa para la infancia en Bogotá piensa la calidad de la educación, como un camino para luchar contra la pobreza, la inequidad, la injusticia y la exclusión social. Tener como fundamento de la Política Educativa para la Infancia el derecho a una educación de calidad, implicó entender la educación como un sistema complejo integral y permanente, que convoca para la atención y educación de la infancia a todos los sectores de la administración pública, incluyendo los espacios de los jardines y los colegios, en el cual no solo se construyan aprendizajes, sino que se reconozca desde la diferencia al niño y niña como ciudadano autónomo en el marco de la cultura global, nacional y local.

Así, la calidad de la educación como propuesta alternativa, es entendida como un derecho social que promueve y orienta las acciones de la política y los procesos de enseñanza y aprendizaje hacia la dignificación de los sujetos

\footnotetext{
44 Ibid., p. 72.

45 El profesor Abel Rodríguez Céspedes, ve la posibilidad en su trayectoria como secretario de educación, de consolidar y concretar las propuestas no solo de la Ley General de Educación de 1994 y la Constitución Política de 1991, sino aquellas que emergieron del Movimiento Pedagógico y del Magisterio Colombiano, por ello los Planes Sectoriales de Educación "Bogotá, una Gran Escuela" y Educación de Calidad para una Bogotá Positiva", recoge y materializan las propuestas que desde la década de los 80 , se han considerado como una reforma educativa que propende por la defensa de la educación pública con calidad.

46 Idem

47 Alcaldía Mayor de Bogotá, D.C., 2008, op. cit., p. 72
} 
y brinda a los niños y niñas la posibilidad de aprender en condiciones dignas, promoviendo ambientes de aprendizaje enriquecidos.

Esta propuesta alternativa de Bogotá, centró también sus acciones en la posibilidad de materializar en el espacio escolar los fines y objetivos de la educación acordados por la sociedad y establecidos en la Constitución Política de 1991 y la Ley General de Educación (Ley 115 de 1994), a través de diferentes proyectos $^{48}$ buscando que los currículos escolares estuvieran orientados por los intereses y demandas de aprendizaje de los niños y las niñas, así como por sus condiciones cognitivas, socio afectivas y físicas, con lo cual se vincula a la institución educativa y a los maestros al gran propósito, no solo de mejorar la calidad de la educación, sino que esta contribuye real y efectivamente a elevar las condiciones de vida de la población y a hacer de la educación un ejercicio democrático, participativo y de desarrollo social para todos.

Esta idea de calidad de la educación en Bogotá, es continuada en el Plan sectorial de educación 2012-2016 "Bogotá Humana" de la administración de Gustavo Petro. Sin embargo, en el Plan Sectorial de Educación 2012 - 2016, el énfasis se hace en ofrecer una educación de calidad para "los niños, niñas y jóvenes en desventaja y en situación de vulnerabilidad, pues constituye la principal palanca para reducir la desigualdad"49. Emergiendo nuevamente en el discurso de la política educativa, la condición o situación de irregularidad como principio para la formulación de programas y proyectos de política.

- Otra propuesta alternativa y que se ha mantenido en el tiempo es la que refiere a la gratuidad de la educación oficial en el Distrito. En cuanto al discurso de la gratuidad en la educación en Bogotá, inicia como un elemento alternativo e innovador en la educación oficial de la ciudad, que se posiciona en la administración de Luis Eduardo Garzón "Bogotá sin Indiferencia, 2004-2008" y tiene continuidad y mayor cobertura en las siguientes administraciones. De esta forma el Distrito se convierte en pionero en el país en implementar la gratuidad en la educación oficial y así lo refieren los balances de gestión en el sector.

Bogotá ha logrado uno de los principales objetivos del milenio: garantizar que la educación primaria sea universal, es decir gratuita y accesible para todos, sin discriminación. (...) A partir del 2007 y en adelante, la educación será totalmente gratuita para los estudiantes de preescolar y primaria, como para todos los estudiantes de Sisben 1, aquellos con necesidades educativas especiales y los que han sido víctimas de conflicto. ${ }^{50}$

48 El Plan Sectorial de Educación de Calidad para una Bogotá Positiva, propuso como ejes de la Política Educativa para elevar la calidad de la educación: 1. Educación de calidad y pertinencia para vivir mejor 2. Acceso y Permanencia para todos y todas. 3. Mejoramiento de la infraestructura y dotación de colegios (Alcaldía Mayor de Bogotá, D.C., Plan Sectorial de Educación 2008 - 2012: educación de calidad para una Bogotá Positiva, 2008).

49 Alcaldía Mayor de Bogotá, D.C, Plan Sectorial de Educación, 2012 - 2016 "Calidad para todos y todas", (Bogotá: Secretaría de Educación Distrital, 2012), 2.

50 Alcaldía Mayor de Bogotá, D.C. Informe de Gestión sector de Educación 2004- 2007, (Bogotá: Secretaría de Educación Distrital, 2007), 25. 
Podemos decir que la Política pública para la infancia en Colombia, se ha desarrollado entre tensiones y discontinuidades, especialmente porque estas políticas están orientadas a remediar las condiciones intolerables de la vida y a restituir los derechos de los niños, y solo hasta hace unos pocos años la política y las leyes para la infancia en el país consideran acciones para prevenir las condiciones de riesgo y vulnerabilidad de los niños y niñas.

- Una tensión manifiesta en el discurso hegemónico de la Política Educativa en Colombia, es la que se configura entre la idea de una política asistencialista y la idea una política de educación para la primera infancia. El asistencialismo centra su prioridad en la atención de los niños y niñas en cuanto, alimentación, cuidado e higiene. Idea que encuentra su correlato en la propuesta de una política para la infancia en situación de irregularidad y vulnerabilidad que se presentan en el discurso del Estado desde la década de los $70 \mathrm{y}$ se ha mantenido durante los últimos treinta años, aunque matizada por la noción de "restitución y garantía de los derechos" de los niños y niñas en condiciones desfavorables.

Un criterio de la política que tiene sus orígenes en las condiciones de vida de nuestros niños, el mantenimiento del conflicto armado y la cultura de violencia hacia la infancia, haciéndolo un discurso hegemónico, en el cual el cuidado de los niños y niñas en primera instancia era responsabilidad exclusiva de la familia, y luego pasa a ser responsabilidad del Estado, como garante de derechos y suplencia de las condiciones materiales "En relación con la primera infancia el Estado debe ocuparse de asegurar la vida y la supervivencia de los niños y niñas, diseñar mecanismos que aseguren su atención nutricional, servicios de salud, un entorno familiar responsable y respetuoso, y cuidado oportuno y adecuado que permita a los más pequeños estar en espacios seguros y positivos mientras sus padres y madres trabajan" 51

Esta tensión entre el asistencialismo como una propuesta hegemónica y la educación para el desarrollo integral del niño y la niña como una propuesta alternativa, encuentra en la Política Educativa de Bogotá un punto de equilibrio, entre el discurso de atención integral, en este sentido, la Secretaría de Educación Distrital menciona que "la educación no se agota con la prestación de un servicio institucional en el ámbito de la escuela, sino que además exige la creación de unas condiciones satisfactorias para el cuidado de la salud, la seguridad, la nutrición básica y el respeto por todos los derechos fundamentales" ${ }^{25}$ de los niños y niñas consagrados en la Constitución y el ámbito internacional; perspectiva que es asumida por la Política Nacional para la Infancia De cero a siempre.

De igual forma, otra tensión presente, en el marco de la Política Educativa para la Infancia en Colombia, refiere a la promulgación de los lineamientos curriculares los cuales tiene como objetivo mejorar la enseñanza y los aprendizajes

51 Secretaría de Educación Distrital, Lineamientos Primer Ciclo de Educación Formal en Bogotá, (Bogotá: Alianza Global, 2006) 3.

52 Íbid. 
en la educación preescolar y orientar la práctica pedagógica. Una propuesta que se articula desde lo hegemónico, en tanto estos documentos en Colombia han cobrado una importancia significativa desde 1994, como orientadores del hacer y el decir de la enseñanza y el aprendizaje en las instituciones educativas y el aula de clase. Aunque como lo señala el Ministerio de Educación Nacional, en los documentos de lineamientos curriculares, estos no pretenden ser una receta nacional para la elaboración del currículo y el plan de estudio en las instituciones educativas, señalan aspectos fundamentales para que las comunidades puedan construir y organizar participativamente su propuesta curricular de modo que constituyan un instrumento para el desarrollo del gran proyecto institucional. ${ }^{53}$

No obstante el mismo documento, señala que "En virtud de la autonomía curricular las comunidades educativas ejercen ahora ese poder y tienen la oportunidad de hacer esa selección negociada (...) Por consiguiente el currículo incluirá además de los elementos de la cultura local, regional y nacional, elementos de la cultura planetaria" 54

Como correlato de este discurso de la Política Nacional, en el nivel local en Bogotá, D.C. en el año 2011 se presenta el documento titulado "Lineamiento pedagógico para la educación inicial en el Distrito". En este documento se encuentra una propuesta que promueve la articulación entre las prácticas pedagógicas y las acciones que devienen de la política planteando un sentido de "cambio y progreso" hacia una mejora en materia de educación para la infancia, como se señala a continuación:

El contenido de este Lineamiento es abordado desde la experiencia institucional acumulada, el conocimiento y las apuestas conceptuales del Distrito Capital en relación con la pedagogía y la educación dirigida a la primera infancia, al igual que los aportes teóricos, politicos y normativos del orden nacional e internacional. Esta publicación, pretende llegar principalmente a los jardines infantiles, colegios y ámbitos en los cuales la primera infancia está presente. Por ello brinda orientaciones que apoyen el trabajo de las maestras y los maestros y que aporten en la estructuración de su quehacer pedagógico. Es un imperativo la generación de espacios de reflexión y discusión docente que tengan impacto sobre el discurso y las prácticas que han caracterizado la educación inicial ${ }^{55}$.

En los lineamientos para la educación inicial ${ }^{56}$ se reconoció e incorporó el concepto de diversidad que ha orientado el trabajo, la educación, la protección y el cuidado de los niños y niñas de 0 a 6 años, garantizando con ello el pleno desarrollo de sus capacidades, desde la diferencia, la inclusión y el reconocimiento a la diversidad cultural.

\footnotetext{
53 Ministerio de Educación Nacional, 1998, op.cit., p. 40

54 Ibíd., p. 41.

55 Alcaldía Mayor de Bogotá, Lineamientos pedagógico y curricular para la educación inicial en el Distrito (Bogotá: Secretaría Distrital de Integración Social, 2011) 6.

56 Ibíd.
} 


\section{CONCLUSIÓN}

En este camino, hoy de cara a las reformas educativas, se constata que la educación de la infancia es una tarea inaplazable, que aunque ha sido abordada por la política pública, frente a los retos y compromisos asumidos a nivel internacional, como lo señala la Misión de Ciencia, Educación y Desarrollo ${ }^{57}$, la educación inicial continúa presentando problemáticas como: Baja cobertura y distribución inequitativa; desarticulación entre la educación preescolar formal y los diferentes programas de atención a la infancia; prevalencia de la falsa idea de que es fácil educar a los niños pequeños y que por ello cualquiera puede hacerlo, sin tomar conciencia de la importancia decisiva que tiene la educación temprana en el desarrollo humano, ni en los perjuicios que una formación inicial defectuosa puede causar; carencia de infraestructura y apoyo tecnológico y de material pedagógico adecuado para el fomento de la creatividad en las primeras fases del ciclo vital; inexistencia de sistemas de detección temprana de talentos y vocaciones especiales, y de competencias o deficiencias mentales y sensoriales.

Así mismo, después de veinte años de haber sido promulgada la Ley General de Educación (Ley 115/1994), el Ministerio de Educación, aún no ha implementado y garantizado el derecho a la educación de la primera infancia de tres grados: pre jardín, jardín y transición ${ }^{58}$ en todo el territorio nacional y en la educación pública, con lo cual no se cumple el principio en donde superar las brechas de inequidad social, cultural y económica en nuestro país, pasa por garantizar una educación para la infancia, que se comprometa con la eliminación de la desigualdad permitiendo a todos los niños, el ingreso temprano a la escuela y el acceso a las herramientas de la cultura indispensables para superar el atraso generado en los primeros años de vida.

A partir del año 2000, cada gobierno local y nacional, ha dado a la Política de Infancia en el país, un nombre y un énfasis; haciendo que el discurso sobre los derechos y la práctica jurídica sobre la infancia, se convierta en un discurso constitutivo de enunciados, dominios objetos y acciones sociales, económicas, culturales y jurídicas hacia la infancia, con el fin de conseguir mejoras sustanciales en la calidad de vida de la niñez a partir de la garantía de los derechos y de las posibilidades de su aplicación. Así, la Política Educativa para la Infancia en el país, se ha convertido en un instrumento del Estado para realizar o cumplir con sus obligaciones y para la sociedad civil ha configurado un marco legítimo que les permite exigir al Estado la restitución, la garantía y la satisfacción de sus necesidades que son traducidas en derechos.

57 República de Colombia, Misión Ciencia, Educación y Desarrollo; Colombia al Filo de la Oportunidad, (Bogotá: Editorial Magisterio, 1997), 139 -140.

58 Aunque esta estrategia ha sido punto en la agenda política de los diferentes gobiernos y es una de las condiciones para garantizar la equidad y la igualdad en oportunidades de desarrollo de los niños y las niñas según la Declaración Mundial sobre Educación para Todos: marco de acción para satisfacer las necesidades básicas de aprendizaje realizada en Jomtiem 1990, en Colombia ha sido uno de los programas de mayor dificultad en su implementación en el ámbito público, en tanto hacen falta infraestructura adecuada y formación del personal encargado de la atención. La educación inicial, sigue siendo atendida en su mayoría por el sector privado. 
Las propuestas alternativas en Colombia y específicamente en Bogotá, han instaurado nuevos discursos pedagógicos y políticos en relación con la educación y ha logrado integrar la diversidad cultural, social y política del país a la problemática de la garantía del derecho a la educación con calidad para los niños y las niñas de nuestro país.

\section{FUENTES}

Alcaldía Mayor de Bogotá. Quiéreme bien, quiéreme hoy Política por la calidad de vida de niños, niñas y adolescentes en Bogotá 2004 -2008. Bogotá: 2004.

Alcaldía Mayor de Bogotá D.C. Plan Sectorial de Educación 2004 - 2008, Bogotá: una gran escuela para que los niños, niñas y jóvenes aprendan más y mejor. Bogotá: Secretaría Distrital de Educación, 2004.

Alcaldía Mayor de Bogotá, D.C. Informe de Gestión sector de Educación 2004- 2007. Bogotá: Secretaría de Educación Distrital, 2007.

Alcaldía Mayor de Bogotá, D.C. Plan Sectorial de Educación 2008 -2012: educación de calidad para una Bogotá Positiva. Bogotá: Secretaria de Educación Distrital, 2008.

Alcaldía Mayor de Bogotá. Lineamientos pedagógico y curricular para la educación inicial en el Distrito. Bogotá: Secretaría Distrital de Integración Social, 2011.

Alcaldía Mayor de Bogotá, D.C Plan Sectorial de Educación, 2012 -2016: Calidad para todos y todas. Bogotá: Secretaría de Educación Distrital, 2012.

Secretaría de Educación Distrital. Lineamientos Primer Ciclo de Educación Formal en Bogotá. Bogotá: Alianza Global, 2006.

Ministerio de Educación Nacional. Lineamientos generales de procesos curriculares para la construcción de comunidades educativas autónomas. Bogotá: Imprenta Nacional, 1994.

Ministerio de Educación Nacional. Lineamientos Curriculares: Preescolar. Bogotá: Ministerio de Educación Nacional, 1998.

Ministerio de Educación Nacional. Guía operativa para la prestación del servicio de atención integral a la primera infancia. Guía 35. Bogotá: Imprenta Nacional, 2009.

Presidencia de la República de Colombia, Estrategia de atención integral a la primera infancia: fundamentos políticos, técnicos y de gestión. Bogotá: Imprenta Nacional, 2013.

Ley 7 de 1979: Por la cual se dictan normas para la protección de la Niñez, se establece el Sistema nacional de Bienestar Familiar y se reorganiza el Instituto Colombiano de Bienestar Familiar ICBF. República de Colombia, 1979.

Ley 115: Ley general de Educación. Congreso de Colombia: República de Colombia, febrero 8 de 1994.

Resolución 2343 de junio 5 de 1996. República de Colombia: Ministerio de Educación Nacional, 1996.

Ley 1098: Código de la Infancia y la Adolescencia. República de Colombia, 2006. 


\section{REFERENCIAS}

Braudel, Fernando, La larga duración en La historia y las ciencias sociales. Madrid: Alianza Editores, 1979.

Bloch, Marc Introducción a la Historia. Buenos Aires: Fondo de Cultura Económico, 1982

Castoriadis, Cornelius. Sujeto y Verdad en mundo histórico social: Seminarios 1986 - 1987. Buenos Aires: Fondo de Cultura Económica de Argentina S.A., 2002.

Castoriadis, Cornelius. La institución Imaginaria de la sociedad. Argentina: Fábula Tusquets Editores, 2013.

Febvre, Lucien. Combates por la historia. España: Editorial Ariel, 1982.

Jiménez, Absalón. Emergencia de la infancia contemporánea 1968-2006. Bogotá: Universidad Francisco José de Caldas, 2012.

Gómez Sollano, et. al. Reconfiguración de lo educativo en América Latina: experiencias Pedagógicas alternativas. México: Universidad Nacional Autónoma de México, 2013.

Gramsci, Antonio. El materialismo histórico y la filosofía de Benedetto Croce. México: Juan Pablos Editor, 1975.

Laclau, Ernesto y Chantal Mouffe. Hegemonía y Estrategia socialista. Hacia la radicalización de la democracia. Buenos Aires: Fondo de Cultura Económica, 2004.

Pérez Murcia, Luis Eduardo, Rodrigo Uprimmy y César Rodríguez Garavito. Los Derechos Sociales en Serio: hacia un diálogo entre derechos y políticas públicas. Bogotá: Centro de Estudios de Derecho, Justicia y Sociedad, Instituto para la Investigación y el desarrollo pedagógico-IDEP, 2007.

República de Colombia. Misión Ciencia, Educación y Desarrollo; Colombia al Filo de la Oportunidad. Bogotá: Editorial Magisterio, 1997.

Rincón, Cecilia. "Imaginarios de Infancia, políticas públicas y prácticas pedagógicas". Tesis doctoral en Pedagogía, Universidad Nacional Autónoma de México - UNAM, 2013.

Rincón, Cecilia, et al., Imaginarios de infancia y la formación de maestros. Bogotá: Editorial Magisterio, 2008.

Rodríguez, Abel. 20 años de la Ley General de Educación: resultados y Posibilidades. Bogotá: Editorial Magisterio, 2015.

Roth, André-Noël. Políticas Públicas, Formulación e Implementación. Bogotá: Ediciones Aurora, 2002.

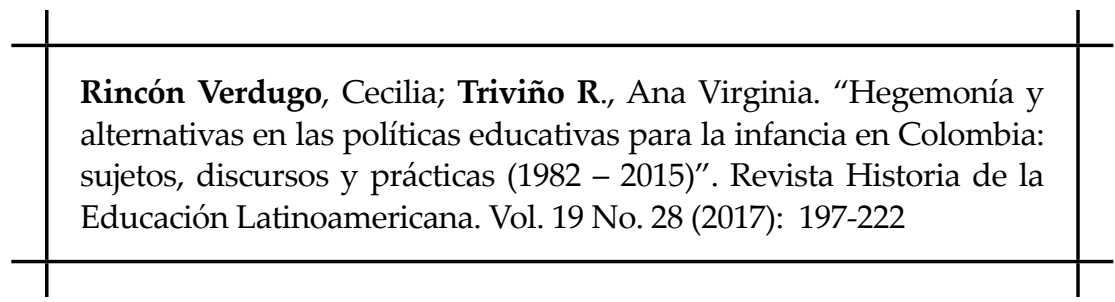

